\title{
Tumor deposit is a poor prognostic indicator in patients who underwent simultaneous resection for synchronous colorectal liver metastases
}

This article was published in the following Dove Press journal:

OncoTargets and Therapy

22 January 2015

Number of times this article has been viewed

\author{
Qi Lin" \\ Ye Wei ${ }^{\#}$ \\ Li Ren ${ }^{\#}$ \\ Yunshi Zhong ${ }^{\#}$ \\ Chunzhi Qin \\ Peng Zheng \\ Pingping $X u$ \\ Dexiang Zhu \\ Meiling Ji \\ Jianmin Xu \\ Department of General Surgery, \\ Zhongshan Hospital, Fudan University, \\ Shanghai, People's Republic of China \\ \#These authors contributed equally to \\ this work
}

Correspondence: Jianmin $\mathrm{Xu}$

$\mathrm{Tel}+86$ I35 $0 \mid 984869$

$\mathrm{Fax}+8602164038038$

Email xujmin@aliyun.com
Background: Tumor deposits are one of the important influencing factors among the different editions of Tumor, Node, Metastasis classification. Incidence and prognosis of tumor deposits in stage I, II, and III colorectal cancer patients has been explored. The aim of this study was to determine the prognostic value of tumor deposits in stage IV colorectal cancer patients who underwent simultaneous resection for synchronous colorectal liver metastases (SCRLM).

Methods: Clinicopathological and outcome data of 146 consecutive SCRLM patients who underwent simultaneous R0 resection between July 2003 and July 2013 were collected from our prospectively established SCRLM database. The prognostic value of tumor deposits was evaluated by Kaplan-Meier and Cox regression analysis.

Results: Tumor deposits were detected in $41.8 \%(61 / 146)$ of these SCRLM patients. Tumor deposits were significantly correlated with lymph node metastasis and nerve invasion of the primary tumors $(P=0.002, P=0.041$; respectively). The Kaplan-Meier survival analysis revealed that the overall survival (OS) and disease-free survival (DFS) of SCRLM patients with tumor deposits were significantly poorer than those with no tumor deposits $(P=0.039, P=0.001$; respectively). And with multivariate analysis, we found that positive tumor deposits were significantly associated with shorter DFS independent of lymph node status $(P=0.002)$. Subgroup analysis found that of the 57 SCRLM patients with negative lymph node status, the OS and DFS of patients with positive tumor deposits were significantly shorter than those with negative tumor deposits ( $P=0.002$ and $P=0.031$, respectively). Of the 89 patients with positive lymph node status, the OS of patients with tumor deposits was not significantly different than those without tumor deposits $(P=0.965)$; however, the DFS of patients with tumor deposits was significantly shorter than those with no tumor deposits $(P=0.034)$.

Conclusion: Tumor deposits may be an independent adverse prognostic factor in SCRLM patients who underwent simultaneous $\mathrm{R} 0$ resection.

Keywords: tumor deposits, synchronous colorectal liver metastases, prognostic factors

\section{Introduction}

Even in the developed countries including United States of America, colorectal cancer $(\mathrm{CRC})$ is the third most common cancer diagnosed in both men and women, and the second leading cause of cancer deaths. ${ }^{1}$ The International Union Against Cancer (UICC)/American Joint Committee on Cancer (AJCC) Tumor, Node, Metastasis (TNM) classification is a worldwide applied system for cancer staging. This system for assessing tumor stage which was adopted over 50 years ago provides accurate prognostic information and helps determine the treatment decisions for CRC. ${ }^{2}$

In the past few years, the TNM staging system for CRC has been changed several times. One of the most radical changes is regarding tumor deposits. Tumor deposits 
are defined as focal aggregates of cancer nodules located in the pericolic region or in perirectal fat. These nodules are discontinuous with the primary tumor and are not associated with lymph nodes. Whether the tumor deposits should be considered as lymph node involvement when staging the disease has been the hotspot of discussion for many years which resulted in changes in classification of the disease in subsequent editions of the TNM staging system. Tumor deposits were first introduced in the fifth edition (TNM5) in $1997,{ }^{3}$ in which tumor deposits greater than $3 \mathrm{~mm}$ in diameter were considered as lymph node metastases. In the subsequent edition (TNM6), ${ }^{4}$ the $3 \mathrm{~mm}$ standard was withdrawn and replaced by a definition of tumor deposits based on contour. In the current TNM classification (TNM7), the previous contour rule was abandoned and the new TNM staging system stated that only T1 and T2 lesions that were positive for tumor deposits but lacked regional lymph node metastasis will be classified as N1c. ${ }^{5}$ This induces a significant change in the TNM staging system: patients with T1 or T2 tumors that meet the N1c criteria are escalated from a stage I to stage IIIa. Similarly, patients with T3 and T4a tumors that meet these same criteria are escalated from a stage II to stage IIIb. Finally, patients with T4b tumors with these additional features are now classified as stage IIIc.

Whether the prognostic value of TNM7 is better than other editions and whether this change is reproducible still needs to be validated. Furthermore, the newest classification does not indicate how to classify the patients with both lymph node metastases and positive tumor deposits. It is still unknown whether, in the different stages of the disease, the prognostic impact of tumor deposits is different. Presently, several reports have demonstrated that tumor deposits in stage II and III CRC patients are a poor prognostic indicator, ${ }^{6-12}$ but no study has focused on stage IV CRC patients.

In the present study, we first investigated the incidence and prognosis of tumor deposits in patients who underwent simultaneous R0 resection for synchronous colorectal liver metastases (SCRLM).

\section{Materials and methods}

\section{Study population}

We reviewed our prospectively collected SCRLM database between July 2003 and July 2013. The selection criteria for simultaneous resection have been reported previously: ${ }^{13}$ expected radical resection of primary cancer and marginnegative resection of liver metastases, no unresectable extrahepatic metastases and adequate volume of the post-operative liver. Patients who underwent previous hepatic resections, ablations of the liver metastases, died during the perioperative period, or had incomplete materials were also excluded from this study. All of the patients included in this study acquired simultaneous R0 resection for both their primary cancer and liver metastases which was confirmed by the postoperative pathology. This study was approved by the institutional review board of Zhongshan Hospital. All of the patients provided written consent.

\section{Histologic evaluation of tumor deposits}

For each patient, all slides were reviewed to evaluate the presence of tumor deposits together with other pathological factors. Existence of tumor deposits was defined as nodules located in the pericolic/perirectal adipose tissue of the bowel specimen without lymphocyte aggregates or in the mesocolic/mesorectal specimens harvested and collected as lymph nodes for evaluation of metastasis. Cancer nodules adjacent to metastatic lymph nodes presumed to be correlated with the process of lymph node metastasis were not considered as tumor deposits, and cancer nodules restricted to lymphatic or venous structures or tumor foci less than $5 \mathrm{~mm}$ of the foremost edge of the primary tumor were not considered as tumor deposits. ${ }^{7,12}$

\section{Data collection}

Clinicopathological data from all patients were collected from our prospectively collected SCRLM database. The duration of perioperative chemotherapy was also recorded. The follow-up regimen included routine computed tomography scans of the chest, abdomen, and pelvis and regular colonoscopic surveillance. Disease recurrence was recorded on the basis of clinical, endoscopic or radiological findings at the time of diagnosis. The date of last follow-up, vital status, and recurrence were recorded for all patients. Overall survival (OS) was calculated from the date of diagnosis to the date of death due to CRC or last follow-up. Disease-free survival (DFS) was calculated from the date of surgery until the date of documented disease recurrence.

\section{Statistical analysis}

Summary statistics were obtained using established methods and are presented as percentages or mean values with standard deviations. Categorical data are summarized as percentages and were analyzed using chi-squared analysis or Fisher's exact test. OS and DFS were analyzed using Kaplan-Meier analysis; survival curves were compared using the log-rank test. Univariate and multivariate analyses were performed using the Cox proportional hazards model. The prognostic factors with $P<0.10$ in univariate analysis were entered into 
the Cox proportional hazards model using stepwise selection to identify independent predictors. All of the statistical analyses were performed using SPSS 16.0 software (SPSS Inc., Chicago, IL, USA). Two-sided $P$-values were calculated, and $P<0.05$ was considered significant.

\section{Results}

\section{Clinicopathological characteristics of the SCRLM patients}

From July 2003 to July 2013, we identified 146 patients who underwent simultaneous R0 resection of SCRLM. Detailed clinicopathological data of the 146 patients is shown in Table 1 . The majority of patients were male $(56.8 \%)$ and younger than 60.0 years old $(65.8 \%)$. Most patients presented with primary colon tumor $(69.2 \%)$. The average number of metastases was $1.88 \pm 1.18(1.0-7.0)$. The average size of the largest metastasis was $3.80 \pm 2.29 \mathrm{~cm}(0.5-15 \mathrm{~cm})$. Positive tumor deposits were detected in $41.8 \%$ (61/146) of these patients. Various clinicopathologic characteristics were assessed and compared according to tumor deposits status. We found that lymph node metastasis and the nerve invasion of the primary tumors were significantly correlation with the presence of tumor deposits ( $P=0.002, P=0.041$; respectively) (Table 1).

\section{Operative details and perioperative chemotherapy}

For the primary tumor operations, $38.4 \%(56 / 146)$ of patients underwent right hemicolectomy, 34.5\% (48/146) of patients underwent left hemicolectomy, $28.8 \%(42 / 146)$ of patients underwent proctectomy. For the liver operations, $77.4 \%(113 / 146)$ underwent wedge resection, $17.1 \%$ (25/146) underwent hemihepatectomy, $1.4 \%$ (2/139) underwent extended hepatectomy, 4.1\% (6/146) underwent an unknown extent of hepatic resection. As for complications, a total of $30.1 \%(44 / 146)$ of patients had 57 complications as follows: ascites (11), subphrenic fluid (8), pleural effusion (7), wound infection and fat liquefaction (5), small bowel obstruction (5), pneumonia and atelectasis (5), intra-abdominal infection (3), hemorrhage/hematoma (3), transient hepatic dysfunction (2), bile leakage (2), intestinal leakage (2), and others (4). All of the complications were successfully treated medically or by percutaneous drainage. Of the patients analyzed, $23.3 \%$ (34/146) of patients received preoperative chemotherapy, and all patients received adjuvant chemotherapy. The routinely used chemotherapy regiments were FOLFOX (oxaliplatin, folinic acid and fluorouracil); FOLFIRI (irinotecan, folinic acid and fluorouracil); and XELOX (capecitabine and oxaliplatin).
Table I The correlation between the clinicopathological factors and the status of tumor deposits in patients who underwent simultaneous resection for synchronous colorectal liver metastases

\begin{tabular}{|c|c|c|c|c|c|}
\hline \multirow[t]{3}{*}{ Variables } & \multicolumn{2}{|c|}{ Patients } & \multicolumn{2}{|c|}{ Tumor deposits } & \multirow[t]{3}{*}{$P$-value } \\
\hline & No & $\%$ & Positive & Negative & \\
\hline & $\overline{146}$ & $\overline{100}$ & 61 & 85 & \\
\hline \multicolumn{5}{|l|}{ Age (years) } & 0.596 \\
\hline$\leq 60$ & 96 & 65.8 & 42 & 54 & \\
\hline$>60$ & 50 & 34.2 & 19 & 31 & \\
\hline \multicolumn{5}{|l|}{ Sex } & 0.913 \\
\hline Male & 83 & 56.8 & 35 & 48 & \\
\hline Female & 63 & 43.2 & 26 & 37 & \\
\hline \multicolumn{5}{|l|}{ Tumor location } & 0.424 \\
\hline Colon & 101 & 69.2 & 40 & 61 & \\
\hline Rectum & 45 & 30.8 & 21 & 24 & \\
\hline \multicolumn{5}{|l|}{ Histological type } & 0.304 \\
\hline Adenocarcinoma & 124 & 84.9 & 54 & 70 & \\
\hline $\begin{array}{l}\text { Mucinous } \\
\text { adenocarcinoma }\end{array}$ & 22 & 15.1 & 7 & 15 & \\
\hline \multicolumn{5}{|l|}{ Tumor differentiation } & 0.227 \\
\hline Well, moderate & 78 & 53.4 & 29 & 49 & \\
\hline Poor and others & 68 & 46.6 & 32 & 36 & \\
\hline \multicolumn{5}{|c|}{ Primary tumor $(T)$ stage } & 1.000 \\
\hline TI, T2 & 6 & 4.1 & 2 & 4 & \\
\hline $\mathrm{T} 3, \mathrm{~T} 4$ & 140 & 95.9 & 59 & 81 & \\
\hline \multicolumn{5}{|c|}{ Primary nodal $(\mathrm{N})$ stage } & 0.002 \\
\hline Absent & 57 & 39.0 & 15 & 42 & \\
\hline Present & 89 & 61.0 & 46 & 43 & \\
\hline \multicolumn{5}{|l|}{ Vascular invasion } & 0.113 \\
\hline Absent & 121 & 82.9 & 47 & 74 & \\
\hline Present & 25 & 17.1 & 14 & 11 & \\
\hline \multicolumn{5}{|l|}{ Nerve invasion } & 0.041 \\
\hline Absent & 129 & 88.4 & 50 & 79 & \\
\hline Present & 17 & 11.6 & II & 6 & \\
\hline \multicolumn{5}{|l|}{ No of metastases } & 0.130 \\
\hline$\leq 3$ & 129 & 88.4 & 51 & 78 & \\
\hline$\geq 4$ & 17 & 11.6 & 10 & 7 & \\
\hline \multicolumn{5}{|l|}{ Largest metastasis } & 0.673 \\
\hline$<5 \mathrm{~cm}$ & 105 & 71.9 & 45 & 60 & \\
\hline$\geq 5 \mathrm{~cm}$ & 41 & 28.1 & 16 & 25 & \\
\hline \multicolumn{5}{|c|}{ Carcinoembryonic antigen } & 0.952 \\
\hline$\leq 5 \mathrm{ng} / \mathrm{mL}$ & 46 & 31.5 & 19 & 27 & \\
\hline$>5 \mathrm{ng} / \mathrm{mL}$ & 98 & 68.5 & 41 & 57 & \\
\hline
\end{tabular}

\section{OS analysis}

Follow-up information was obtained for the 146 patients through July 2013. The 5 year OS rate was $47.0 \%$. The median follow-up period was 36.1 months. At the last follow-up, $29.5 \%(43 / 146)$ of patients had died and 51.4\% (75/146) of patients experienced tumor recurrence. Of those patients $34.9 \%(51 / 146)$ had recurrence in the liver only, $6.8 \%$ $(10 / 146)$ had recurrence in the lung only, and 9.6\% (14/146) had recurrence in other sites. 
To investigate the prognostic value of positive tumor deposits in the SCRLM patients, we compared OS according to the status of tumor deposits with Kaplan- Meier survival analysis. This analysis revealed that the OS of the CRC patients who were positive for tumor deposits was significantly poorer than those patients who were negative for tumor deposits ( $P=0.039$, Figure 1A).

In order to estimate the clinical significance of various prognostic factors that might influence survival in the study population, univariate analyses were performed for OS in the 146 patients with SCRLM using the Cox proportional hazards model. The following factors were significantly associated with poorer OS: positive lymph nodes, vascular invasion, nerve invasion, tumor deposits around the primary tumor, and the number of liver metastases $(\geq 4)$. The prognostic factors with $P<0.10$ in univariate analysis were then entered into the Cox proportional hazards model using stepwise selection to identify independent predictors. We found that positive lymph nodes $(P=0.001)$, vascular invasion $(P=0.001)$, and the number of liver metastases $(P=0.004)$ were significantly associated with poorer prognosis. The details of the univariate and multivariate analyses are shown in Table 2.

\section{DFS analysis}

The 5 year DFS of the 146 CRLMs patients was $36.0 \%$. We also compared DFS according to the presence of tumor deposits with a Kaplan-Meier survival analysis. This analysis revealed that the DFS of SCRLM patients with tumor deposits was significantly poorer than those patients negative for deposits $(P=0.001$; Figure $1 \mathrm{~B})$.

In univariate analyses, the number of liver metastases $(\geq 4)$, extrahepatic metastases resection, and the presence of tumor deposits were significantly associated with shorter DFS. The prognostic factors with $P<0.10$ in the univariate analysis were entered into the Cox proportional hazards model using stepwise selection to identify independent predictors. We found that the number of liver metastases $(\geq 4)$ and the existence of tumor deposits were significantly associated with shorter DFS ( $P=0.007, P=0.002$; respectively). The details of the univariate and multivariate analyses are shown in Table 3.

\section{Subgroup survival analysis according to the status of lymph node metastasis and tumor deposits}

In our study, of the 57 patients with negative lymph nodes, the OS and DFS of patients positive for tumor deposits were significantly shorter than those negative for tumor deposits, as analyzed with the Kaplan-Meier method ( $P=0.002$ and $P=0.031$, respectively) (Figure $2 \mathrm{~A}$ and $\mathrm{B}$ ). When analyzing the 89 patients with positive lymph nodes using the same method, the OS was not significantly different $(P=0.965)$
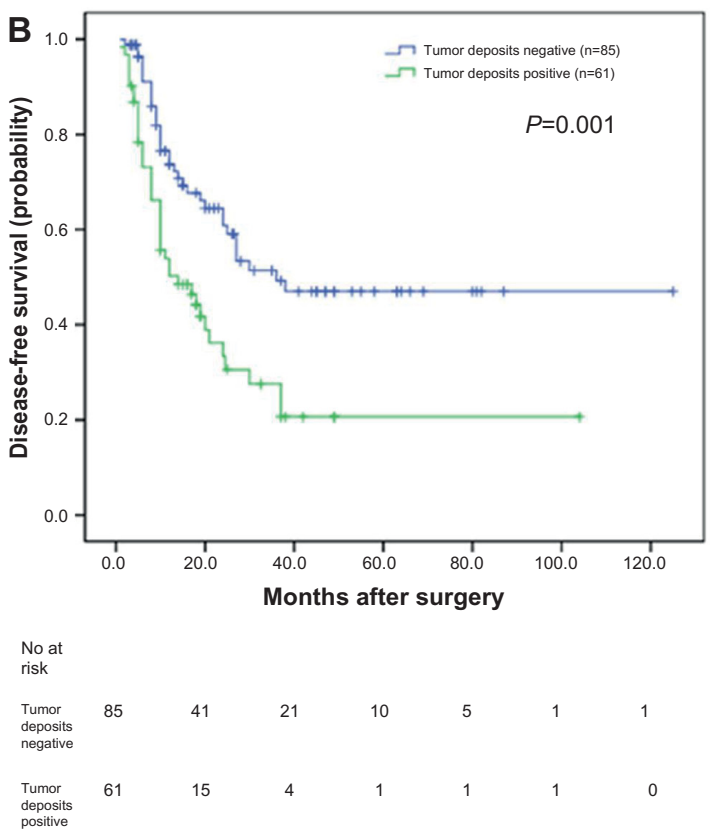

Figure I Analyses of overall survival and disease-free survival according to the status of tumor deposits in synchronous colorectal liver metastases (SCRLM) patients. Notes: (A) Kaplan-Meier analyses of overall survival according to status of tumor deposits in SCRLM patients ( $n=\mid 46$; $P=0.039)$. (B) Kaplan-Meier analyses of disease-free survival according to status of tumor deposits in SCRLM patients $(n=\mid 46 ; P=0.00 I)$. 
Table 2 Univariate and multivariate analyses of associations between clinicopathological factors and overall survival in patients who underwent simultaneous resection for synchronous colorectal liver metastases

\begin{tabular}{|c|c|c|c|c|c|c|}
\hline \multirow[t]{2}{*}{ Prognostic factor } & \multicolumn{3}{|c|}{ Univariate analysis } & \multicolumn{3}{|c|}{ Multivariate analysis } \\
\hline & HR & $95 \% \mathrm{Cl}$ & $P$ & HR & $95 \% \mathrm{Cl}$ & $\mathbf{P}$ \\
\hline Age $(>60: \leq 60)$ & 0.623 & $0.320-1.214$ & 0.165 & & & \\
\hline Sex (female:male) & 1.620 & $0.890-2.949$ & 0.115 & & & \\
\hline Primary tumor site (rectum:colon) & 1.314 & $0.706-2.443$ & 0.389 & & & \\
\hline $\begin{array}{l}\text { Histological type (mucinous } \\
\text { adenocarcinoma: adenocarcinoma) }\end{array}$ & 0.795 & $0.313-2.023$ & 0.631 & & & \\
\hline $\begin{array}{l}\text { Tumor differentiation (well, moderate: } \\
\text { poor and others) }\end{array}$ & 1.564 & $0.850-2.880$ & 0.151 & & & \\
\hline Primary tumor $(\mathrm{T})$ stage $(\mathrm{T} 3, \mathrm{~T} 4: \mathrm{T}, \mathrm{T} 2)$ & 2.585 & $0.355-18.803$ & 0.348 & & & \\
\hline Primary nodal (N) stage (NI, N2:N0) & 3.304 & $1.530-7.132$ & 0.002 & 4.200 & $1.912-9.224$ & $<0.001$ \\
\hline Vascular invasion (positive:negative) & 2.616 & $1.308-5.230$ & 0.007 & 3.561 & $1.688-7.514$ & 0.001 \\
\hline Nerve invasion (positive:negative) & 2.569 & $1.068-6.177$ & 0.035 & 1.622 & $0.651-4.042$ & 0.299 \\
\hline No of liver metastases $(\geq 4: \leq 3)$ & 1.485 & $0.984-5.643$ & 0.022 & 3.408 & I.478-7.859 & 0.004 \\
\hline Size of liver metastases $(\geq 5 \mathrm{~cm}:<5 \mathrm{~cm})$ & 2.589 & $1.145-5.854$ & 0.237 & & & \\
\hline Extrahepatic metastases resection (yes:no) & 2.198 & $0.677-7.134$ & 0.190 & & & \\
\hline CEA (>5 ng/mL: $>5 \mathrm{ng} / \mathrm{mL})$ & 1.824 & $0.896-3.715$ & 0.098 & 1.647 & $0.805-3.368$ & 0.172 \\
\hline Chemotherapy (postoperative:perioperative) & 1.077 & $0.56 \mathrm{I}-2.069$ & 0.824 & & & \\
\hline Tumor deposits (positive:negative) & 1.859 & $1.019-3.389$ & 0.043 & $1.54 \mid$ & $0.820-2.895$ & 0.179 \\
\hline
\end{tabular}

Abbreviations: $\mathrm{HR}$, hazard ratio; $\mathrm{Cl}$, confidence interval.

(Figure 3A); however, the DFS of patients positive for tumor deposits was significantly shorter than those negative for tumor deposits $(P=0.034)$ (Figure 3B).

\section{Discussion}

Presently, the latest seventh TNM staging system for CRC has caused great controversy. Some studies suggest that the seventh TNM edition does not provide greater accuracy in predicting the prognosis of CRC patients. ${ }^{14-16}$ However, other studies indicated that the seventh TNM edition has better prognostic validity than the sixth TNM edition. ${ }^{17-19}$ Tumor deposit is one of the important influencing factors among the different editions. How to correctly define and differentiate positive tumor deposits and lymph node metastases

Table 3 Univariate and multivariate analyses of associations between clinicopathological factors and disease-free survival in patients who underwent simultaneous resection for synchronous colorectal liver metastases

\begin{tabular}{|c|c|c|c|c|c|c|}
\hline \multirow[t]{2}{*}{ Prognostic factor } & \multicolumn{3}{|c|}{ Univariate analysis } & \multicolumn{3}{|c|}{ Multivariate analysis } \\
\hline & HR & $95 \% \mathrm{Cl}$ & $P$ & HR & $95 \% \mathrm{Cl}$ & $\mathbf{P}$ \\
\hline Age $(>60: \leq 60)$ & 0.671 & $0.408-1.104$ & 0.116 & & & \\
\hline Sex (female:male) & 1.529 & $0.97 \mathrm{I}-2.409$ & 0.067 & 1.541 & $0.976-2.432$ & 0.063 \\
\hline Primary tumor site (rectum:colon) & 1.313 & $0.819-2.104$ & 0.258 & & & \\
\hline $\begin{array}{l}\text { Histological type (mucinous } \\
\text { adenocarcinoma: adenocarcinoma) }\end{array}$ & 0.620 & $0.298-1.292$ & 0.202 & & & \\
\hline $\begin{array}{l}\text { Tumor differentiation (well, moderate: } \\
\text { poor and others) }\end{array}$ & 1.423 & $0.898-2.255$ & 0.133 & & & \\
\hline Primary tumor $(\mathrm{T})$ stage $(\mathrm{T} 3, \mathrm{~T} 4: \mathrm{T} 1, \mathrm{~T} 2)$ & 1.539 & $0.484-4.893$ & 0.465 & & & \\
\hline Primary nodal (N) stage (NI, N2:N0) & 1.611 & $0.99 \mid-2.620$ & 0.054 & 1.404 & $0.827-2.384$ & 0.209 \\
\hline Vascular invasion (positive:negative) & 1.482 & $0.828-2.652$ & 0.185 & & & \\
\hline Nerve invasion (positive:negative) & 1.453 & $0.722-2.926$ & 0.295 & & & \\
\hline No of LMs $(\geq 4: \leq 3)$ & 2.333 & $|.25|-4.35 \mid$ & 0.008 & 2.380 & $1.268-4.469$ & 0.007 \\
\hline Size of LM $(\geq 5 \mathrm{~cm}:<5 \mathrm{~cm})$ & 1.420 & $0.872-2.312$ & 0.159 & & & \\
\hline Extrahepatic metastases resection (yes:no) & 2.670 & $1.068-6.675$ & 0.036 & 1.716 & $0.66 I-4.454$ & 0.267 \\
\hline CEA $(>5 \mathrm{ng} / \mathrm{mL}:>5 \mathrm{ng} / \mathrm{mL})$ & 1.429 & $0.868-2.352$ & 0.160 & & & \\
\hline Chemotherapy (postoperative:perioperative) & $\mathrm{I} .108$ & $0.663-1.852$ & 0.696 & & & \\
\hline Tumor deposits (positive:negative) & 2.149 & $1.360-3.396$ & 0.001 & 2.080 & $1.316-3.290$ & 0.002 \\
\hline
\end{tabular}

Abbreviations: $\mathrm{HR}$, hazard ratio; $\mathrm{Cl}$, confidence interval. 

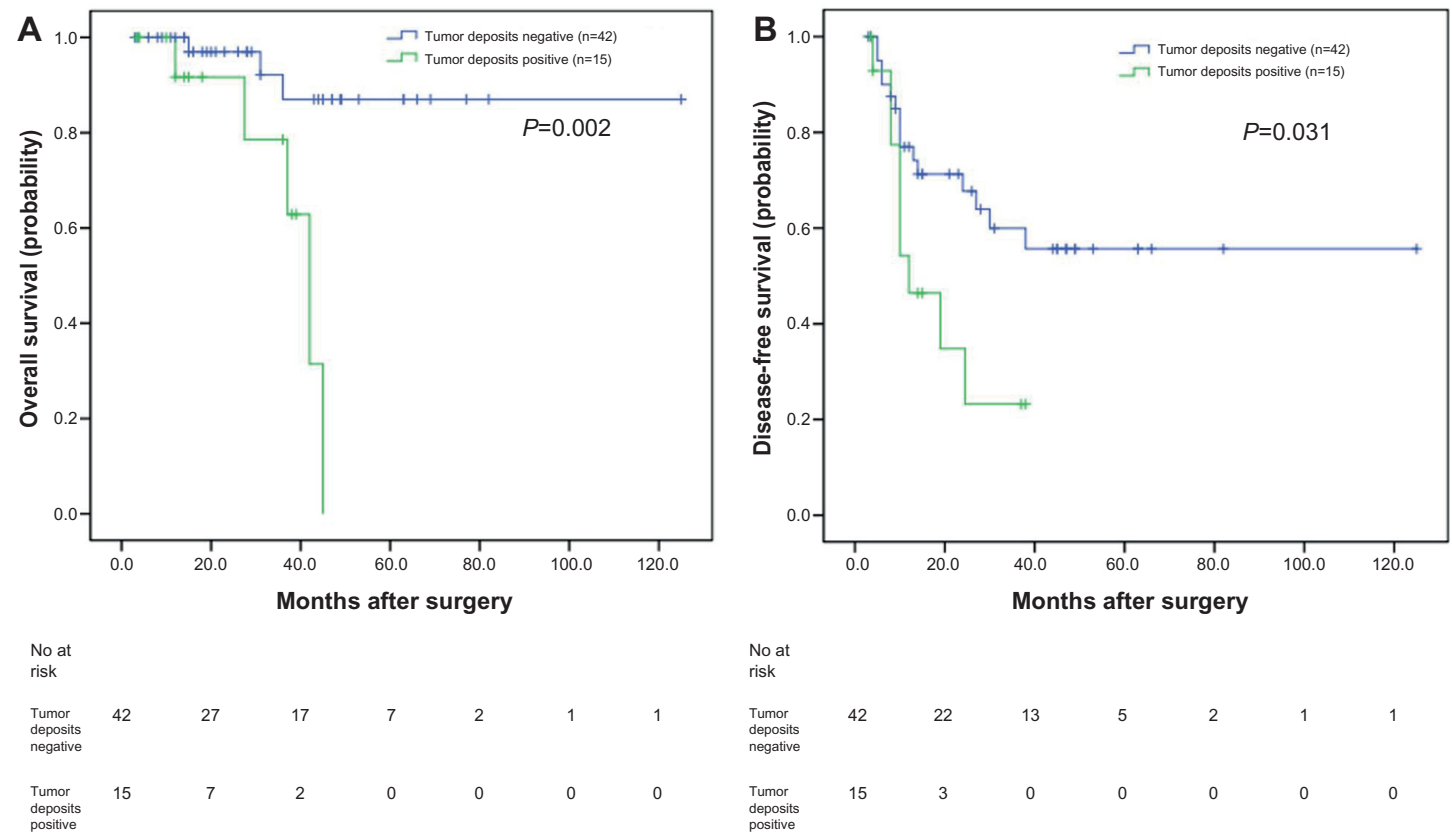

Figure 2 Analyses of overall survival and disease-free survival according to the status of tumor deposits in synchronous colorectal liver metastases (SCRLM) patients with negative lymph node.

Notes: (A) Kaplan-Meier analyses of overall survival according to status of tumor deposits in SCRLM patients with negative lymph node ( $n=57$; $P=0.002$ ). (B) Kaplan-Meier analyses of disease-free survival according to status of tumor deposits in SCRLM patients with negative lymph node ( $n=57 ; P=0.03 \mathrm{I}$ ).

has confused researchers and clinicians. Some studies have demonstrated that classifying the positive tumor deposits as a type of $\mathrm{N}$ factor irrespective of contours can simplify the tumor staging system by enhancing diagnostic objectivity which improves prognostic accuracy. ${ }^{10,12,20}$
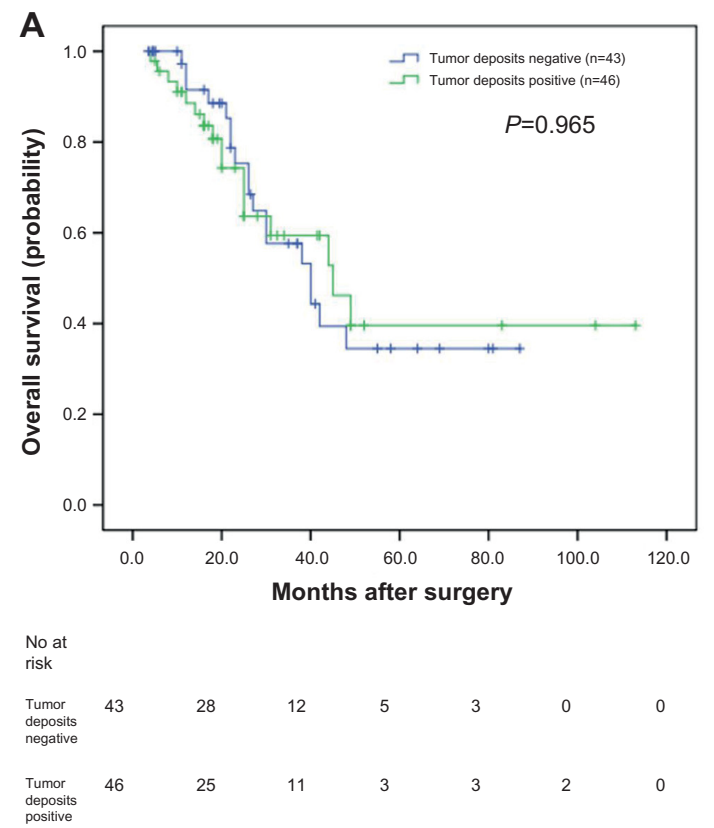

The incidence of tumor deposits in the stage II and III CRC patients varies from $4.5 \%$ to $46.9 \%$ determined in part by the definitions and the methods of examination. ${ }^{15,21,22}$ It is clear that tumor deposits can present in early tumor stages. Ratto et $\mathrm{al}^{22}$ found that tumor deposits were present

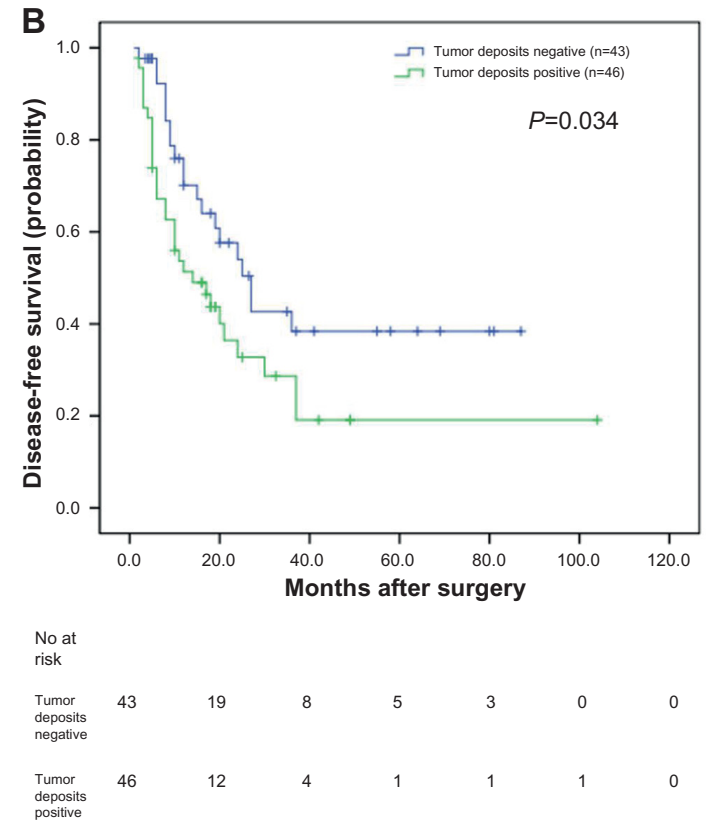

Figure 3 Analyses of overall survival and disease-free survival according to the status of tumor deposits in synchronous colorectal liver metastases (SCRLM) patients with positive lymph node.

Notes: (A) Kaplan-Meier analyses of overall survival according to status of tumor deposits in SCRLM patients with positive lymph node ( $\mathrm{n}=89$; $P=0.965)$. (B) Kaplan-Meier analyses of disease-free survival according to status of tumor deposits in SCRLM patients with positive lymph node $(\mathrm{n}=89 ; \mathrm{P}=0.034)$. 
in $18.8 \%$ of TNM stage I tumors and $46.9 \%$ of TNM stage II tumors. The incidence of patients with tumor deposits increased with higher tumor stage. ${ }^{11}$ In our study, tumor deposits were detected in $41.8 \%$ of the SCRLM patients who underwent simultaneous $\mathrm{R} 0$ resection. Another study about CRC lung metastasis detected that $54.1 \%$ of patients were positive for tumor deposits. ${ }^{23}$ In our study, we found that the presence of tumor deposits was significantly correlated with primary lymph metastasis and nerve invasion. These results demonstrate that tumor deposits might be an invasive focus of aggressive tumor cells which originated from lymphatic channels and nerve sheath infiltrations. ${ }^{22}$ We also observed a statistically significant difference in the tumor deposit subgroup's survival rate according to the status of lymph nodes. These results suggest that tumor deposits should be considered independently from lymph node metastasis because of a possible difference in the impact on survival between these two modes of discontinuous spread. ${ }^{24}$

Additionally, the seventh edition of TNM staging may have weakened the prognostic value of tumor deposits. Belt et al ${ }^{11}$ suggested that all negative lymph node stage II patients with tumor deposits, regardless of their size and shape, should be classified as stage III and that adjuvant chemotherapy should be considered for these patients because of their high risk of disease recurrence. Ueno $\mathrm{H}$ et $\mathrm{al}^{8}$ reported that the 5 year DFS was $85.0 \%$ in $695 \mathrm{pT} 3 / \mathrm{T} 4$ patients with CRC without tumor deposits and $59.5 \%$ in those with tumor deposits $(P<0.001)$. Multivariate analyses showed that tumor deposits affected DFS independent of $\mathrm{T}$ and $\mathrm{N}$ stages. Tong et $\mathrm{al}^{6}$ have suggested that patients who are categorized as T3N2bM0TD (+) and T4N2bM0TD (-/+) may be reclassified as stage IV due to their similar poor prognosis; moreover, these authors did not consider the number of tumor deposits to be a prognostically significant parameter. In our study, OS and DFS of the patients with positive tumor deposits were significantly shorter than those negative for tumor deposits. And of the patients with positive lymph nodes, the DFS of the patients positive for tumor deposits was significantly shorter than those negative for tumor deposits. Of the patients with negative lymph nodes, the OS and DFS of the patients positive for tumor deposits were significantly shorter than those who were negative. With multivariate analysis, we found that the presence of tumor deposit was significantly associated with shorter DFS independent of lymph node status. We are in agreement with another study about the CRC lung metastasis patients who underwent resection. ${ }^{23}$ These results together suggest that tumor deposits should be treated differently from lymph node metastasis because of a possible difference in impact on survival.
In conclusion, the presence of tumor deposits was an independent adverse prognostic factor for SCRLM patients who underwent simultaneous R0 resection. Our study was a single institution retrospective study and the number of patients was small. More research needs to be done on how to define and judge the tumor deposits to decrease the interobserver variation.

\section{Disclosure}

The authors have no conflicts of interest to disclose.

\section{References}

1. Siegel R, Naishadham D, Jemal A. Cancer statistics, 2013. CA: A Cancer Journal for Clinicians. 2013;63(1):11-30.

2. Nagtegaal ID, Quirke P, Schmoll HJ. Has the new TNM classification for colorectal cancer improved care? Nature reviews. Clinical Oncology. 2012;9(2):119-123.

3. Sobin LH, Fleming ID. TNM Classification of Malignant Tumors, fifth edition (1997). Union Internationale Contre le Cancer and the American Joint Committee on Cancer. Cancer. 1997;80(9):1803-1804.

4. Wittekind C, Compton CC, Greene FL, Sobin LH. TNM residual tumor classification revisited. Cancer. 2002;94(9):2511-2516.

5. Edge SB, Compton CC. The American Joint Committee on Cancer: the 7th edition of the AJCC cancer staging manual and the future of TNM. Ann Surg Oncol. 2010;17(6):1471-1474.

6. Tong LL, Gao P, Wang ZN, et al. Is the seventh edition of the UICC/ AJCC TNM staging system reasonable for patients with tumor deposits in colorectal cancer? Ann Surg. 2012;255(2):208-213.

7. Nagayoshi K, Ueki T, Nishioka Y, et al. Tumor deposit is a poor prognostic indicator for patients who have stage II and III colorectal cancer with fewer than 4 lymph node metastases but not for those with 4 or more. Diseases of the Colon and Rectum. 2014;57(4):467-474.

8. Ueno H, Hashiguchi Y, Shimazaki H, et al. Peritumoral deposits as an adverse prognostic indicator of colorectal cancer. American Journal of Surgery. 2014;207(1):70-77.

9. Gopal P, Lu P, Ayers GD, Herline AJ, Washington MK. Tumor deposits in rectal adenocarcinoma after neoadjuvant chemoradiation are associated with poor prognosis. Modern Pathology: An Official Journal of the United States and Canadian Academy of Pathology, Inc. 2014;27(9):1281-1287.

10. Ueno H, Mochizuki H, Shirouzu K, et al. Multicenter study for optimal categorization of extramural tumor deposits for colorectal cancer staging. Ann Surg. 2012;255(4):739-746.

11. Belt EJ, van Stijn MF, Bril H, et al. Lymph node negative colorectal cancers with isolated tumor deposits should be classified and treated as stage III. Ann Surg Oncol. 2010;17(12):3203-3211.

12. Ueno H, Mochizuki H, Shirouzu K, et al. Actual status of distribution and prognostic impact of extramural discontinuous cancer spread in colorectal cancer. J Clin Oncol. 2011;29(18):2550-2556.

13. Xu J, Qin X, Wang J, et al. Chinese guidelines for the diagnosis and comprehensive treatment of hepatic metastasis of colorectal cancer. J Cancer Res Clin Oncol. 2011;137(9):1379-1396.

14. Nitsche U, Maak M, Schuster T, et al. Prediction of prognosis is not improved by the seventh and latest edition of the TNM classification for colorectal cancer in a single-center collective. Ann Surg. 2011;254(5):793-800.

15. Nagtegaal ID, Tot T, Jayne DG, et al. Lymph nodes, tumor deposits, and TNM: are we getting better? J Clin Oncol. 2011;29(18):2487-2492.

16. Hari DM, Leung AM, Lee JH, et al. AJCC Cancer Staging Manual 7th edition criteria for colon cancer: do the complex modifications improve prognostic assessment? Journal of the American College of Surgeons. 2013;217(2):181-190. 
17. Kim KH, Yang SS, Yoon YS, Lim SB, Yu CS, Kim JC. Validation of the seventh edition of the American Joint Committee on Cancer tumor-nodemetastasis (AJCC TNM) staging in patients with stage II and stage III colorectal carcinoma: analysis of 2511 cases from a medical centre in Korea. Colorectal Dis. 2011;13(8):e220-e226.

18. Ueno H, Mochizuki H, Akagi Y, et al. Optimal colorectal cancer staging criteria in TNM classification. J Clin Oncol. 2012;30(13):1519-1526.

19. Gao P, Song YX, Wang ZN, et al. Is the prediction of prognosis not improved by the seventh edition of the TNM classification for colorectal cancer? Analysis of the surveillance, epidemiology, and end results (SEER) database. BMC Cancer. 2013;13:123.

20. Song YX, Gao P, Wang ZN, et al. Can the tumor deposits be counted as metastatic lymph nodes in the UICC TNM staging system for colorectal cancer? PloS One. 2012;7(3):e34087.
21. Nagtegaal ID, Quirke P. Colorectal tumour deposits in the mesorectum and pericolon; a critical review. Histopathology. 2007;51(2):141-149.

22. Ratto C, Ricci R, Rossi C, Morelli U, Vecchio FM, Doglietto GB. Mesorectal microfoci adversely affect the prognosis of patients with rectal cancer. Dis Colon Rectum. 2002;45(6):733-742.

23. Ishikawa K, Hashiguchi Y, Mochizuki H, Ozeki Y, Ueno H. Extranodal cancer deposit at the primary tumor site and the number of pulmonary lesions are useful prognostic factors after surgery for colorectal lung metastases. Dis Colon Rectum. 2003;46(5):629-636.

24. Goldstein NS, Turner JR. Pericolonic tumor deposits in patients with T3N+MO colon adenocarcinomas: markers of reduced disease free survival and intra-abdominal metastases and their implications for TNM classification. Cancer. 2000;88(10):2228-2238.
OncoTargets and Therapy

\section{Publish your work in this journal}

OncoTargets and Therapy is an international, peer-reviewed, open access journal focusing on the pathological basis of all cancers, potential targets for therapy and treatment protocols employed to improve the management of cancer patients. The journal also focuses on the impact of management programs and new therapeutic agents and protocols on

\section{Dovepress}

patient perspectives such as quality of life, adherence and satisfaction. The manuscript management system is completely online and includes a very quick and fair peer-review system, which is all easy to use. Visit http://www.dovepress.com/testimonials.php to read real quotes from published authors. 